\title{
Bioremediation of malathion in soil by mixed Bacillus culture
}

\author{
Baljinder Singh, Jagdeep Kaur, Kashmir Singh
}

Department of Biotechnology, Panjab University, Chandigarh, India

Email: gilljwms2@gmail.com

Received 10 March 2013; revised 4 April 2013; accepted 9 May 2013

Copyright (C) 2013 Baljinder Singh et al. This is an open access article distributed under the Creative Commons Attribution License, which permits unrestricted use, distribution, and reproduction in any medium, provided the original work is properly cited.

\begin{abstract}
Degradation of a pesticide, malathion, in soil by $\mathrm{Ba}$ cillus sp has been reported during current study. A simple and highly sensitive reverse phase HPLC-UV (High pressure liquid chromatography-Ultraviolet) method was used for determination of malathion degradation in soil. The bioremediation of was performed in malathion contaminated sterile and nonsterile soil and it was found that $84.81 \%$ and $74.11 \%$ of malaoxon, respectively, from malathion concentration of $1.5 \% \mathrm{~kg}^{-1}$ soil was degraded by strain PU after 7 days. Similarly, $63.31 \%$ and $57.14 \%$ of malaoxon in sterile and nonsterile soil respectively, from malathion concentration of $1.5 \% \mathrm{~kg}^{-1}$ soil was degraded by strain KB2 after 7 days. Bioremediation of malathion in soil using strain KB1 have already discussed in the previous study (Singh et al., 2012). Regardless of soil sterilization, incorporation of bacterial strain in malathion containing soil resulted in higher level of degradation of malathion. Bioremediation of malathion in soil was maximum for mixed culture of all three strains.
\end{abstract}

Keywords: Component; Formatting; Style; Styling; Insert

\section{INTRODUCTION}

Malathion [S-(1,2-dicarbethoxyethyl)-O,O-dimethyldithiophosphate], also known as carbophos, maldison and mercaptothion is a nonsystemic, wide-spectrum organophosphorus pesticide used in public health, residential, and agricultural settings [1]. Malathion is suited for the control of sucking and chewing insects of fruits and vegetables, mosquitoes, flies, household insects, animal parasites (ectoparasites), and head and body lice. Malathion is used in veterinary medicine [2] and also as an anti-infective agent [3] to control insect vector-borne diseases such as malaria, dengue and yellow fever. Organochlorine pesticides are banned in many countries including India therefore organophosphate pesticides including malathion are largely used for public health and agricultural purposes. Malathion comes in two forms: a pure form of a colorless liquid and a technical-grade solution (brownish-yellow liquid, commonly used in agricultural). Technical-grade malathion (may contain up to 11 impurities formed during its production and/or storage, some of these impurities, such as isomalathion, have been found to be significantly more toxic than malathion [4]. Malaoxon is an oxygen analogue of malathion which can be found either as an impurity in malathion, or generated during the oxidation of malathion in water, air or soil [1, $5,6]$. Malaoxon is 60 times more toxic than malathion but it degrades quickly than malathion

(http://www.bionity.com/en/encyclopedia/Malathion.htm 1). Malathion was recognized as the first organophosphorous insecticide with highly selective [1,6-8]. Main target of malathion toxicity in animals is nervous system thus indirectly affecting other organs and their functions. Malathion irreversibly inactivates acetylcholinesterase (AChE) enzyme that breaks down acetylcholine, a chemical essential in transmitting nerve impulses across junctions between nerves [5]. Malathion degrading bacterial isolates have already been reported $[1,6,7,9,10]$. Fungi, Penicillium rotatum and Aspergillus niger, metabolized $76 \%$ and $59 \%$ of the malathion in the medium within 10 days through carboxylesteratic hydrolysis as well as by a demethylation process. Two species of rhizobium, $R$. leguminnosaru, $R$. trifolii, were isolated from the Egyptian soil that showed high carboxyesterase activity in the presence of malathion $[11,12]$. It was reported that heterogeneous bacterial population (Flavobacterium meningosepticum, Xanthomonas sp, Comamonas terrigeri, and Pseudomonas cepacia) obtained from river water are capable of degrading malathion [13]. The major metabolite was $\beta$-malathion monoacid with only $1 \%$ of the malathion was transformed to malathion dicarboxylic acid, O,O-dimethyl phosphorodithioic acid, and diethyl male- 
ate. [14] observed that Pseudomonas aeruginosa AA112 is able to use malathion as a sole carbon source with the formation of diethylsuccinate and succinate metabolites. It has been found enzyme carboxylesterase from microbes is responsible for degradation of malathion [1,7]. Degradation products observed in the study were malathion monocarboxylic acid and malathion dicarboxylic acid. Malathion degrades rapidly in soil, with reported halflives in soil ranging from few hours to approximately 1 week [15-17]. [18] reported a range of half-life values of $<1-6$ days for malathion and $3-7$ days for malaoxon in soil. [17] reported that initial degradation of malathion in sterile soils than in an inoculated aqueous system in which malathion did not undergo biodegradation until after a 7-day lag period, indicating that actual biodegradation of the compound requires acclimation by the microbial population. Degradation of malathion in soil is directly related to the adsorption of the compound to the soil surfaces, which serves to catalyze the degradation process and allows for almost immediate degradation of the compound $[15,17]$.This paper is in continuation with our previous study [1], where we have characterized three bacterial isolates Lysinibacillus sp strain KB1 [1] and Bacillus cereus strain PU, Brevibacillus sp strain KB2 [1] for malathion degradation. All three stains, KB1, KB2 and PU were able to degrade malathion effectively in liquid culture. PCR amplification and full sequence analysis of carboxylesterase gene were done in previous study $[1,6]$.

\section{MATERIALS AND METHODS}

\subsection{Soil Characteristics}

The soil sample was collected from at depth $0-20 \mathrm{~cm}$ from Botanical garden Panjab University, Chandigarh, India. Soil samples $(50 \mathrm{~g})$ were taken in a clean preweighed $150 \mathrm{~mL}$ beaker and kept in an oven at $105^{\circ} \mathrm{C} \pm$ $3^{\circ} \mathrm{C}$ for $24 \mathrm{~h}$. Difference in the weight of beaker and soil before and after heating was recorded to calculate moisture content. Soil samples $(20 \mathrm{~g})$ were taken in a clean dry $150 \mathrm{~mL}$ beaker and $50 \mathrm{~mL}$ distilled water was added. The contents were thoroughly mixed by vortexing and $\mathrm{pH}$ of the soil suspension was measured with a digital $\mathrm{pH}$ meter.

\subsection{Calcium Carbonate Determination}

Calcium carbonate determination is soil sample was performed using method as follows adding $10 \mathrm{~mL}$ of $1 \mathrm{~N}$ $\mathrm{HCl}$ solution to one gram of air dry soil in $250 \mathrm{~mL}$ flask.. The mixture was kept for overnight at $40^{\circ} \mathrm{C}-50^{\circ} \mathrm{C} .70$ $\mathrm{mL}$ of deionised $\mathrm{H}_{2} \mathrm{O}$ along with 2 - 3 drops of phenolphthalein indicator $(0.5 \mathrm{~g}$ phenolphthalein in $100 \mathrm{~mL}$ ethanol) was added and titration was done with $1 \mathrm{~N} \mathrm{NaCl}$ solution until slight pink color developed.
Percent Calcium carbonate was calculated using following equation;

$$
\% \mathrm{CaCO}_{3}=\left[\left(10 \times \mathrm{N}_{\mathrm{HCl}}\right)-\left(\mathrm{R} \times \mathrm{N}_{\mathrm{NaOH}}\right)\right] \times 100 / \mathrm{Wt}
$$

where: $\quad \mathrm{N}_{\mathrm{HCl}}=$ Normality of $\mathrm{HCl}$ solution

$$
\mathrm{R}=\text { Volume of } \mathrm{NaOH} \text { solution used }(\mathrm{mL})
$$

$\mathrm{N}_{\mathrm{NaOH}}=$ Normality of $\mathrm{NaOH}$ solution

$\mathrm{Wt}$. = weight of air-dry soil (g)

\subsection{Determination of Organic Matter}

Oraganic matter was determined by when $1 \mathrm{~g}$ of air dry soil was added $10 \mathrm{~mL}$ of $1 \mathrm{~N}$ potassium dichromate solution was added followed by addition $20 \mathrm{~mL}$ of concentrated sulphuric acid and swirled the beaker to mix the suspension. Solution was left undisturbed stand for 30 minutes and $200 \mathrm{~mL}$ deionised water and $10 \mathrm{~mL}$ concentrated orthophosphoric acid was added. Added 12 drops of diphenylamine indicator $(1 \mathrm{~g}$ diphenylamine in 100 $\mathrm{mL}$ concentrated sulfuric acid) with continous stirring on magnetic stirrer and finally mixture was titrated with 0.5 $M$ ferrous ammonium sulphate until color changes from violet-blue to green. Blanks solution was prepared that contained all reagents but no soil.

$\%$ Organic matter in soil was calculated using following equation:

$$
\begin{aligned}
& \mathrm{M}=10 / \mathrm{V}_{\text {blank }} \\
& \% \text { Oxidizable Organic Carbon }(\mathrm{w} / \mathrm{w}) \\
= & {\left[\mathrm{V}_{\text {blank }}-\mathrm{V}_{\text {sample }}\right] \times 0.3 \times \mathrm{M} / \mathrm{Wt} } \\
& \% \text { Total Organic Carbon }(\mathrm{w} / \mathrm{w}) \\
= & 1.334 \% \text { Oxidizable Organic Carbon } \\
& \% \text { Organic Matter }(\mathrm{w} / \mathrm{w}) \\
= & 1.724 \times \% \text { Total Organic Carbon }
\end{aligned}
$$
where:

$\mathrm{M}=$ Molarity of ferrous ammonium sulfate solution

$\mathrm{V}_{\text {blank }}=$ Volume of ferrous ammonium sulfate

solution required to titrate the blank $(\mathrm{mL})$

$\mathrm{V}_{\text {sample }}=$ Volume of ferrous ammonium sulfate

solution required to titrate the sample $(\mathrm{mL})$

$$
\text { Wt. }=\text { Weight of air-dry soil }(\mathrm{g})
$$$$
0.3=3 \times 10^{-3} \times 100
$$

where 3 is the equivalent weight of $\mathrm{C}$.

\subsection{Soil Pre-Treatment}

Soil pre-treatment included sieving to select a particle size lower than $0.5 \mathrm{~mm}$ and air-drying. The larger soil particles were removed to attain soil homogeneity. The drying was performed to facilitate subsequent grinding and to increase contact between the soil and the organic solvent used for extraction. Drying at elevated temperatures was avoided since this can result in losses of vola- 
tile compounds. Prior to its use, soil was autoclaved $\left(121^{\circ} \mathrm{C}\right.$ for $40 \mathrm{~min}$ ).

\subsection{Media and Inoculums Preparation}

A selective minimal salt medium (M1) was prepared containing $0.05 \%$ malathion as a sole source of carbon in addition to $\mathrm{NH}_{4} \mathrm{Cl}(0.05 \%), \mathrm{Na}_{2} \mathrm{HPO}_{4} \cdot 2 \mathrm{H}_{2} \mathrm{O}(0.64 \%)$, $\mathrm{KH}_{2} \mathrm{PO}_{4}(0.025 \%), \mathrm{MgSO}_{4} \cdot 7 \mathrm{H}_{2} \mathrm{O}(0.02 \%), \mathrm{NaCl}(0.05 \%)$, in $100 \mathrm{~mL}$ of distilled water. Malathion solution was sterilized by filtration $(0.4 \mu \mathrm{m})$ and added to autoclaved media after cooling. Bacterial strains KB1, KB2 and PU, growing in LB medium for $12 \mathrm{~h}$, were centrifuged at $5000 \mathrm{~g}$ for $10 \mathrm{~min}$, and the cell pellets were washed twice with fresh M1. After the optical density at $600 \mathrm{~nm}\left(\mathrm{OD}_{600}\right)$ had been adjusted to 1.0 , an inoculum $\left(2 \%, \mathrm{vol} \cdot \mathrm{vol}^{-1}\right)$ was inoculated into soil for bioremediation studies.

\subsection{Degradation of Malathion in Soil}

Subsamples of fresh soil and sterile soil were weighed, and solution of malathion was mixed to obtain a final concentration of $1.5 \% \mathrm{~kg}^{-1}$ soil. Malathion fresh sterile soil was inoculated both separately with strains PU, and $\mathrm{KB} 2$ and mixed culture (approximately $10^{8}$ cells $\cdot \mathrm{g}^{-1}$ of soil). The inoculum $(2 \%)$ was thoroughly mixed with soils under sterile conditions, and the moisture was adjusted to $35 \%\left(\mathrm{w} \cdot \mathrm{w}^{-1}\right.$ of dry weight of soil). Uninoculated soil was used as control. Each soil microcosm was incubated at $30^{\circ} \mathrm{C}$ in the dark. After 7 days, the soil samples were collected (20 g samples in Erlenmeyer flask) and 50 $\mathrm{mL}$ of methanol was added and shaken on a horizontal shaker for $10 \mathrm{~min}$. The contents of the flask were allowed to settle down and the supernatant phase was filtered through Whatman No. 1 filter paper. The filtrate was then concentrated by evaporating the solvent on a rotary vaccum evaporator at $30^{\circ} \mathrm{C}$. The concentration of malathion was detected using reverse phase HPLC $[1,6]$. All experiments were conducted in triplicates.

\section{RESULTS AND DISCUSSION}

\subsection{Characteristics of Soil}

The $\mathrm{pH}$ and moisture content of soil sample collected from botanical garden in the campus of Panjab University was found to be $5.8 \%$ and $30.45 \%$ respectively (Table 1). Calcium carbonate: inorganic carbonate, either as calcium (calcite) or magnesium (dolomite) carbonate or mixtures of both, occurs in soil as results of weathering, or is inherited from parent material. A given weight of soil is reacted with an excess of acid and in this reaction $\mathrm{CO}_{2}$ gas is released and the acid not used in the dissolution of carbonates is back-titrated with sodium hydroxide solution. In the titrimetric method, two equivalent of acid
Table 1. Characteristics of soil used in this study.

\begin{tabular}{lc}
\hline \multicolumn{1}{c}{ Parameters } & Results \\
\hline $\mathrm{pH}$ & 5.8 \\
Moisture & $30.45 \%$ \\
Calcium carbonate & $18 \%$ \\
Organic matter & $5.3 \%$ \\
\hline
\end{tabular}

is assumed to be equivalent to one half mole of $\mathrm{CaCO}_{3}$. Calcium carbonate in the soil sample was found to be $18 \%$.

\subsection{Organic Matter}

Soil organic matter represents the remains of roots, plant material, soil organisms in various stages of decomposition and synthesis, and is variable in composition. Though occurring in relatively small amounts in soils, organic matter has a major influence on soil aggregation, nutrient reserve and its availability, moisture retention and biological activity. Organic matter in the soil sample was found to be $5.3 \%$.

\subsection{Bioremediation of Malathion Contaminated Soil}

Only $7.11 \%$ of the initially added $0.15 \%$ of malathion was degraded in un-inoculated sterilized soil after 7 days (Figure 1(a)). However, after inoculation the sterilized soil with strain PU, the degradation of malathion increased to $70 \%$ during the same period. In fresh soil samples with and without inoculation, the degradation of malaoxon was $77.7 \%$ and $17.8 \%$ after 7 days respectively. In our recent study (Singh et al., 2012), we have reported that after inoculation of sterilized soil with strain KB1, the transformation of malathion increased to $68 \%$ during the same period ( 7 days). In fresh soil samples with and without inoculation, the degradation of malaoxon was 78 and $18 \%$ after 7 days, respectively. After inoculation the sterized soil with strain KB2, the degradation of malathion increased to $54 \%$ after 7 days of incubation (Figure 1(b)). In fresh soil samples, the degradation of malaoxon was increased to $61 \%$. Similarly, after inoculation the sterized soil with all three strains, the degradation of malathion increased to $80 \%$ after 7 days of incubation (Figure 1(c)). In fresh soil samples, the degradation of malaoxon was increased to $87 \%$. Although degradation efficiency of strain PU was more as compared to other two strains yet experiments with bioremediation of soil showed that mixed cultures of all three strains has capabilities to degrade malathion more efficiently. Therefore bioaugmentation with mixed culture would be a promising strategy to clean up malathion contaminated sites. Bioremediation of malathion in soil using all three strains separately and mixed together were 


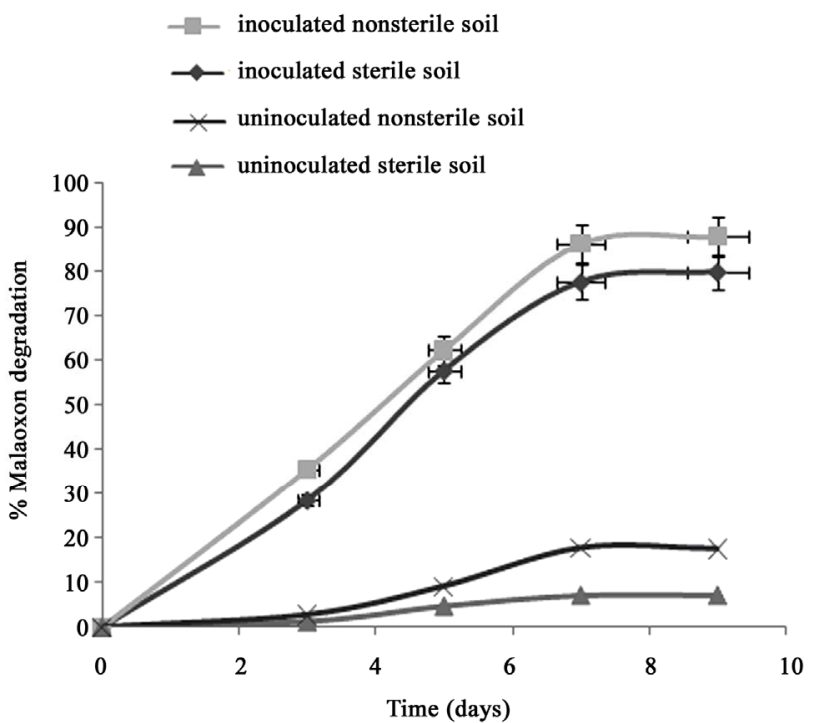

(a)

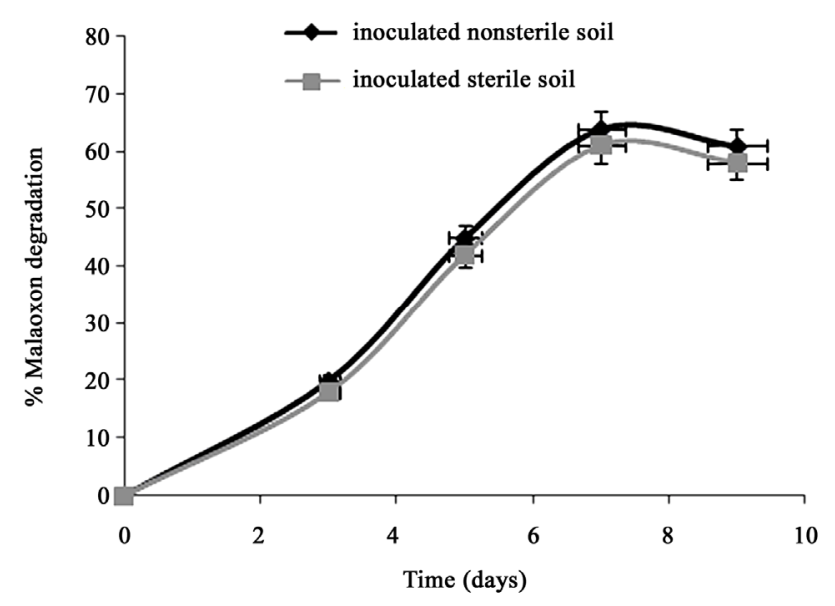

(b)

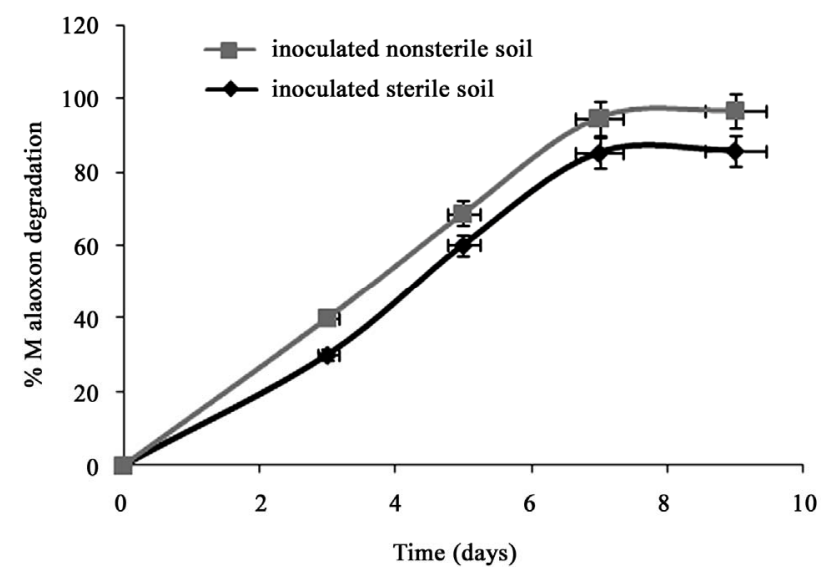

(c)

Figure 1. Degradation of malaoxon in varied soil by (a) strain PU; (b) strain KB1; (c) strain KB2; (d) by mixed culture. Results showed \% malaoxon degradation where initial malaoxon was equal to malathion concentration of $1.5 \% \mathrm{~kg}^{-1}$ soil. Data is presented as mean and standard error of three independent observations $( \pm 0.92)$. carried out in lab scale experiments. When strains were inoculated to the sterilized soil, the degradation of malathion increased, which showed obviously strains enhanced the degradation of malathion. The degradation rate of malathion in fresh soil inoculated with strains was more rapid than without inoculation, which confirmed that all three strains could cooperate well with the indigenous microorganisms to degrade malathion in soil. The results of malathion degradation in soil indicated that mixed culture of all three strains could be used potentially for the bioremediation of malathion contaminated soils.

\section{REFERENCES}

[1] Xie, S., Liu, J.X., Li, L. and Qiao, C.L. (2009) Biodegradation of malathion by Acinetobacter johnsonii MA19 and optimization of cometabolism substrates. Journal of Environmental Sciences, 21, 76-82. doi:10.1016/S1001-0742(09)60014-0

[2] Osweiler, G.D., Carson, T.L., Buck, W.B. and Van Gelder, G.A. (1984) A clinical and diagnostic veterinary toxicology. Kendall/Hunt Publishing Company, Dubuque.

[3] Kamal, Z., Fetyan, N.A.H., Ibrahim, M.A. and El-Nagdy, S. (2008) Biodegradation and detoxification of malathion by of Bacillus thuringiensis MOS-5. Austral Journal of Basic Applied Science, 2, 724-732.

[4] Konrad, J.G., Chesters, G. and Armstrong, D.E. (1969) Soil degradation of malathion, a phosphorodithioate insecticide. Soil Science Society of America, 33, 259-262. doi:10.2136/sssaj1969.03615995003300020026x

[5] Goda, S.K., Elsayed, E.E., Khodair, T.A., El-Sayed, W. and Mohamed, M.E. (2010) Screening for and isolation and identification of malathion-degrading bacteria: Cloning and sequencing a gene that potentially encodes the malathion-degrading enzyme, carboxylestrase in soil bacteria. Biodegradation, 21, 903-913. doi:10.1007/s10532-010-9350-3

[6] Wester, R.C. and Cashman, J.R. (1989) Antiinfective skin preparations: Malathion. In: Damani, L.A., Ed., Sulphur Containing Drugs and Related Organic Compounds, Chemistry, Biochemistry Toxicology Halsted Press, New York.

[7] Bourquin, A.W. (1977) Degaradation of malathion by salt marsh microorganisms. Applied and Environmental Microbiology, 33, 356-362.

[8] Singh, B., Kaur, J. and Singh, K. (2011) Biodegradation of malathion by Brevibacillus sp. strain KB2 and Bacillus cereus. World Journal of Microbiology and Biotechnology, 28, 1133-1141.

[9] Durkin, P.R. (2008) Malathion, human health and ecological risk assessment. SERA TR-052-02-02c.

[10] Singh, B., Kaur, J. and Singh, K. (2012) Transformation of malathion by Lysinibacillus sp. isolated from soil. Biotechnology Letters, 34, 863-867. doi:10.1007/s10529-011-0837-8

[11] Howard, P.H. (1991) Handbook of environmental degradation rates. Lewis Publishers, Chelsea. 
[12] Uygun, U., O'zkara, R., O'zbey, A. and Koksel, H. (2007) Residue levels of malathion and fenitrothion and their metabolites in post harvest treated barley during storage and malting. Food Chemistry, 100, 1165-1169. doi:10.1016/j.foodchem.2005.10.063

[13] Paris, D.F., Lewis, D.L. and Wolfe, N.L. (1975) Rates of degradation of malathion by bacteria isolated from aquatic systems. Environmental Science and Technology, 9, 135-138. doi:10.1021/es60100a011

[14] Gibson, W.P. and Burns, R.G. (1977) The breakdown of malathion in soil and soil components. Microbial Ecology, 3, 219-230. doi:10.1007/BF02010619

[15] Abo-Amer, A.E. (2007) Involvement of chromosomallyencoded genes in malathion utilization by Pseudomonas aeruginosa AA112. Acta Microbiologica et Immunologica Hungarica, 54, 261-277.

$$
\text { doi:10.1556/AMicr.54.2007.3.3 }
$$

[16] Bradman, M.A.S.A., Harnly, M.E. and Goldman, L.R. (1994) Malathion and the malaoxon environmental levels used for exposure assessment and risk characterization of aerial applications to residential areas of southern California, 1989-1990. Journal of Exposure Analysis and Environmental Epidemiology, 4, 49-63.

[17] Mostafa, I.Y., Fakhr, I.M.I. and Bahig, M.E. (1972) Metabolism of organophsphorus insecticides. XIII degaradation of malathion by Rhizobium sp. Archives of Environmental Microbiology, 86, 221.

[18] Mostafa, I.Y., Bahig, M.R.E., Fakhr, I.M.I. and Adam, Y. (1972) Metabolism of organophsphorus insecticides. XIV malathion breakdown by soil fungi. Zeitschrift für Naturforschung, 276, 1115-1116. 